\title{
Analysis of Gastric and Duodenal Eosinophils in Children with Abdominal Pain Related Functional Gastrointestinal Disorders According to Rome III Criteria
}

\author{
Eun Hye Lee, ${ }^{1}$ Hye Ran Yang, ${ }^{1,2 *}$ and Hye Seung Lee ${ }^{3}$ \\ Departments of ${ }^{1}$ Pediatrics and ${ }^{3}$ Pathology, Seoul National University Bundang Hospital, Seongnam, Gyeonggi-do, Korea; and ${ }^{2}$ Department of \\ Pediatrics, Seoul National University College of Medicine, Seoul, Korea
}

\section{Background/Aims}

Abdominal pain-related functional gastrointestinal disorder (AP-FGID) is common in children and adults. However, the mechanism of AP-FGID is not clearly known. Recently, micro-inflammation, especially eosinophilia in the gastrointestinal tract, was suggested in the pathophysiology of AP-FGID in adults. The aim of this study was to evaluate the association of gastric and duodenal eosinophilia with pediatric AP-FGID.

\section{Methods}

In total, 105 pediatric patients with AP-FGID were recruited and classified into 4 subgroups based on the Rome III criteria. Eosinophil counts in the gastric and duodenal tissues of children with AP-FGID were compared to those from normal pathology references or those of children with Helicobacter pylori infection. Tissue eosinophil counts were also compared among the 4 subtypes of AP-FGID.

\section{Results}

Eosinophil counts in the gastric antrum and body were significantly higher in children with AP-FGID than normal reference values. Duodenal eosinophil counts were higher in children with AP-FGID, but not significantly when compared with normal reference values. There were no significant differences in eosinophil counts of the stomach or duodenum among the 4 subtypes of AP-FGID. Eosinophils counts in the gastric antrum and body were significantly higher in children with $\mathrm{H}$. pylori infection than in those with APFGID. Duodenal eosinophilia was prominent in cases of $H$. pylori infection, but not statistically significant when compared with APFGID.

\section{Conclusions}

Our study revealed that gastric eosinophilia is associated with AP-FGID in children, regardless of the subtype of functional abdominal pain. This suggests some contribution of gastrointestinal eosinophils in the development of pediatric AP-FGID.

(J Neurogastroenterol Motil 2016;22:459-469)

\section{Key Words}

Abdominal pain; Child; Eosinophils; Functional gastrointestinal disorder

\section{Received: October 24, 2015 Revised: January 27, 2016 Accepted: March 5, 2016}

(a) This is an Open Access article distributed under the terms of the Creative Commons Attribution Non-Commercial License (http://creativecommons. org/licenses/by-nc/4.0) which permits unrestricted non-commercial use, distribution, and reproduction in any medium, provided the original work is properly cited.

*Correspondence: Hye Ran Yang, MD, PhD Department of Pediatrics, Seoul National University Bundang Hospital, Seoul National University, 82 Gumi-ro 173 beon-gil, Bundang-gu, Seongnam, Gyeonggi-do 13620, Korea Tel: +82-31-787-7285, Fax: +82-31-787-4054, E-mail: hryang@snubh.org 


\section{Introduction}

Abdominal pain-related functional gastrointestinal disorder (AP-FGID) is common in children, with a $16.5 \%$ worldwide pooled prevalence rate based on the Rome III criteria. ${ }^{1}$ A recent meta-analysis showed that prevalence rates of functional abdominal pain disorder were higher in South America (16.8\%) and Asia (16.5\%) than in North America (13.4\%) and Europe (10.5\%). ${ }^{1}$ Children with AP-FGID tend to have a lower quality of life compared to healthy children, and AP-FGID can commonly cause absences from school. ${ }^{2,3}$ AP-FGID is one of the most common gastrointestinal problems seen by pediatric gastroenterologists; however, no medications have been approved to treat this disorder in children. ${ }^{4}$

To date, the mechanism of AP-FGID in the pediatric population is not clearly disclosed. ${ }^{5}$ Several possible mechanisms for the observed symptoms have been suggested, including psychosocial disturbance, abnormal brain-gut interaction, autonomic dysfunction, disordered gastrointestinal motility, visceral hypersensitivity, and immune activation. ${ }^{6-10}$ Recent studies suggest that mild inflammation of the intestines is essentially involved in the pathophysiology of functional gastrointestinal disorder (FGID). ${ }^{11-16}$ Adult studies on FGID, especially functional dyspepsia (FD) and irritable bowel syndrome (IBS), ${ }^{13,14}$ have found that increased infiltration of eosinophils, mast cells, and intraepithelial lymphocytes represent low-grade mucosal inflammation in the gastrointestinal tract. In adult FD patients, gastric eosinophil counts tend not to be significantly increased, but the duodenal eosinophil count and duodenal degranulation is prominently increased. ${ }^{13,16-21}$ On the other hand, several studies also show increased infiltration and degranulation of gastric and duodenal mast cells in adult FD patients. ${ }^{1622-24}$ In adult patients with IBS, most studies demonstrate increased infiltration of mast cells in all parts of the duodenum, ${ }^{14}$ jejunum, ${ }^{25}$ ileum, ${ }^{26}$ and colon, ${ }^{12,27-31}$ with the exception of a few studies. ${ }^{32,33}$ Previous studies also show an increase in T lymphocyte infiltrates. ${ }^{12,14,25,29,30,33}$ Conversely, there appears to be no significant differences in tissue eosinophil counts of patients with IBS. ${ }^{12,14,31,34}$ However, histopathological studies in pediatric patients with AP-FGID are relatively scarce, moreover, the results of some studies are discrepant from those of studies on adults. Friesen et al found that duodenal eosinophil density and degranulation was increased in children with FD. ${ }^{35,36}$ Another study showed that antral eosinophils and mast cells were significantly activated, and that elevated mast cell density of the antrum was associated with delayed gastric emptying and in- creased preprandial dysrhythmia in children with FD. ${ }^{37}$ Schurman et $\mathrm{al}^{38}$ discovered that nocturnal abdominal pain was associated with higher duodenal mast cell density and antral $\mathrm{T}$ lymphocyte counts in children with FD. Mahjoub et $\mathrm{al}^{39}$ detected increased mast cell numbers in the gastric antrum of children with recurrent abdominal pain, which was not classified by the Rome III criteria. To our knowledge, there have been no studies that have compared tissue eosinophil counts in children by considering subtypes of AP-FGID based on the Rome III criteria.

Therefore, the aim of this study was to evaluate the association of gastric and duodenal eosinophils with pediatric AP-FGID, while considering the subtypes of AP-FGID based on the Rome III criteria.

\section{Materials and Methods}

\section{Subjects}

From January 2009 through February 2015, children who visited the pediatric gastroenterology outpatient clinics of our tertiary medical center for chronic recurrent abdominal pain, and who were identified as having AP-FGID, were retrospectively enrolled in this study. In total, 105 pediatric patients with AP-FGID were recruited and classified, based on the Rome III criteria, into 4 subtypes: FD, IBS, abdominal migraine (AM), and functional abdominal pain or syndrome (FAPS). Patients were excluded from this study if they had a significant allergy, including food allergy, asthma, atopic dermatitis, and allergic rhinitis, or if they had underlying organic diseases that can cause gastrointestinal symptoms. Laboratory tests, including complete blood cell counts, erythrocyte sedimentation rate, highly sensitive $\mathrm{C}$ reactive protein, liver function tests, serum amylase and lipase, serum electrolytes, urinalysis, and stool examinations for occult blood and cultures for bacteria and parasites, as well as abdominal X-ray and ultrasonography, were evaluated in all study patients, which revealed normal results in all subjects. All enrolled children also underwent esophagogastroduodenoscopy with biopsies from the gastric antrum, body, and duodenum. Children who had any gross abnormalities, including mucosal nodularity, erosion, or ulceration on endoscopic examination, were also excluded from the study.

Age- and sex-matched healthy children were not recruited as normal controls for this study because healthy children without any gastrointestinal symptoms would not be indicated for esophagogastroduodenoscopy with biopsy, thus they could not undergo esophagogastroduodenoscopy for the study voluntarily. Instead, we 
adopted previously published normal pediatric pathology references as substitution for the data of normal controls. ${ }^{40}$ Additionally, a total of 27 pediatric patients with biopsy-proven Helicobacter pylori infection were also retrospectively recruited as the disease controls. Of the children with $H$. pylori infection, patients with gastric or duodenal ulcers were excluded, whereas patients with mucosal nodularity and/or erythema were included. The Institutional Review Board of Seoul National University Bundang Hospital approved this study protocol.

\section{Endoscopic Biopsy and Histopathology}

Endoscopic biopsies were taken from the gastric antrum, gastric body, and duodenum. Biopsy tissues were immediately fixed in formalin and processed to paraffin wax. Sections were cut at $3 \mu \mathrm{m}$, and stained with hematoxylin and eosin, and the Giemsa stain for H. pylori. Eosinophils were counted in 5 randomly selected high power fields (HPF). Quantification of eosinophils was performed using an Axioskop40 microscope (Mirax-Carl Zeiss, Oberkochen, Germany) at $\times 400$ magnification. Cell counting was performed by 2 pathologists, who were blinded as to the status of the patient, and the average value of the $5 \mathrm{HPF}$ was calculated for each subject. In the stomach, the grades of gastric tissue inflammation was also evaluated according to the severity of mononuclear cell or neutrophil infiltration: absent (grade 0), mild (grade 1), moderate (grade 2), and marked (grade 3), based on the updated Sydney classification. ${ }^{41}$ H. pylori infection was identified by histology and rapid urease testing on gastric biopsy tissues.

Histopathological findings and tissue eosinophil counts in the gastric and duodenal tissues from pediatric AP-FGID cases were compared to those from normal pathology references (normal controls), and to those from children with $H$. pylori infection (disease controls). Tissue eosinophil counts were also compared among the 4 subtypes of AP-FGID. Antral and gastric body eosinophil counts were compared according to degree of antral and gastric body histologic inflammation based on the updated Sydney classification.

\section{Statistical Methods}

All statistical analyses were carried out using PASW statistics software (version 22.0, SPSS Inc, Chicago, IL, USA). Continuous variables are presented as mean and $95 \% \mathrm{CI}$, and categorical variables as a percentage of the total number. Eosinophil counts between normal controls and AP-FGID cases were compared by independent $t$ test. Comparisons of eosinophil counts between each subtype of AP-FGID and normal controls were performed with independent $t$ tests. Differences in tissue eosinophil counts were also evaluated among the 4 subtypes of AP-FGID by the Kruskal-Wallis test. Pair-wise comparisons of tissue eosinophil counts among the subtypes of AP-FGID were done by the Mann-Whitney $U$ test. Comparisons of eosinophil counts between the AP-FGID and $H$. pylori gastritis group were performed with the Mann-Whitney U test. Antral and gastric body eosinophil counts were compared, according to the degree of histologic inflammation in the antrum and gastric body, by Spearman's correlation analysis. For all statistical analyses, a two-sided $P$-value of $<0.05$ was considered statistically significant.

\section{Results}

\section{Patient Characteristics}

A total of 105 children fulfilling the Rome III criteria for APFGID ( 54 boys and 51 girls; median age, 12.6 years; range, 4.5-19.6 years) were recruited and classified as $\operatorname{FD}(n=40), \operatorname{IBS}(n=36)$, $\operatorname{AM}(\mathrm{n}=3), \operatorname{FAPS}(\mathrm{n}=21), \operatorname{FD}+\operatorname{IBS}(\mathrm{n}=2), \operatorname{FD}+\operatorname{AM}(\mathrm{n}$ $=1)$, and IBS + AM $(\mathrm{n}=2)$. Normal controls included 19 children according to the references cases: 8 boys and 11 girls; median age, 12 years (range, 2-17 years). Disease controls with $H$. pylori infection included a total 27 children: 11 boys and 16 girls; median age, 12.2 years (range, 3.9-18.6 years). There were no significant differences among the AP-FGID group, the normal control group,

Table 1. Demographic Characteristics of the Subjects

\begin{tabular}{lcccc}
\hline & $\begin{array}{c}\text { AP-FGID } \\
(\mathrm{n}=105)\end{array}$ & $\begin{array}{c}\text { Normal reference } \\
{[\text { ormal control }]} \\
(\mathrm{n}=19)\end{array}$ & $\begin{array}{c}\text { H. pylori gastritis } \\
{[\text { Disease control }]} \\
(\mathrm{n}=27)\end{array}$ & $\begin{array}{l}11: 16 \\
\text {-value }\end{array}$ \\
\hline Gender (M:F) & $54: 51$ & $8: 11$ & $11.5 \pm 3.9$ & $0.517^{\mathrm{a}}$ \\
Age (mean $\pm \mathrm{SD}, \mathrm{yr})$ & $12.2 \pm 3.1$ & $10.6 \pm 4.2$ & $0.150^{\mathrm{b}}$ \\
\hline
\end{tabular}

${ }^{a}$ Chi-square test.

bANOVA.

AP-FGID, abdominal pain-related functional gastrointestinal disorder; M, male; F, female; H. pylori, Helicobacter pylori. 
A

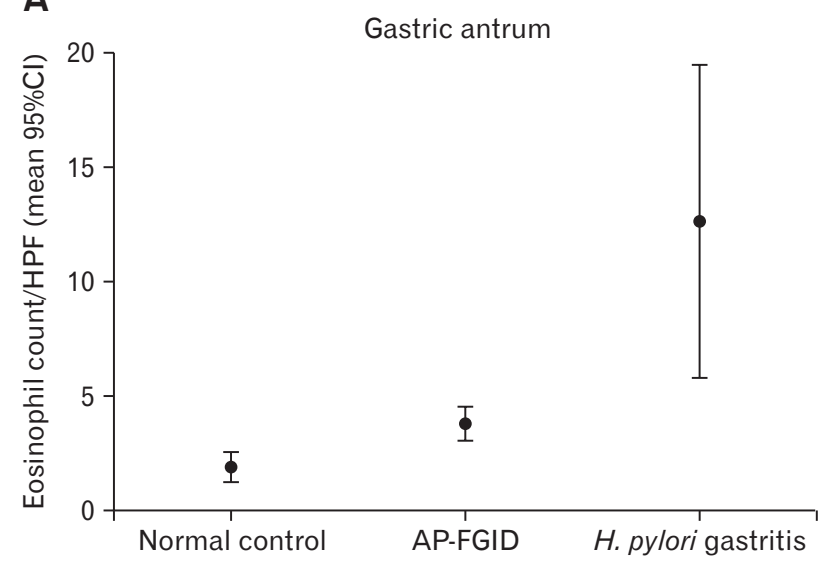

A

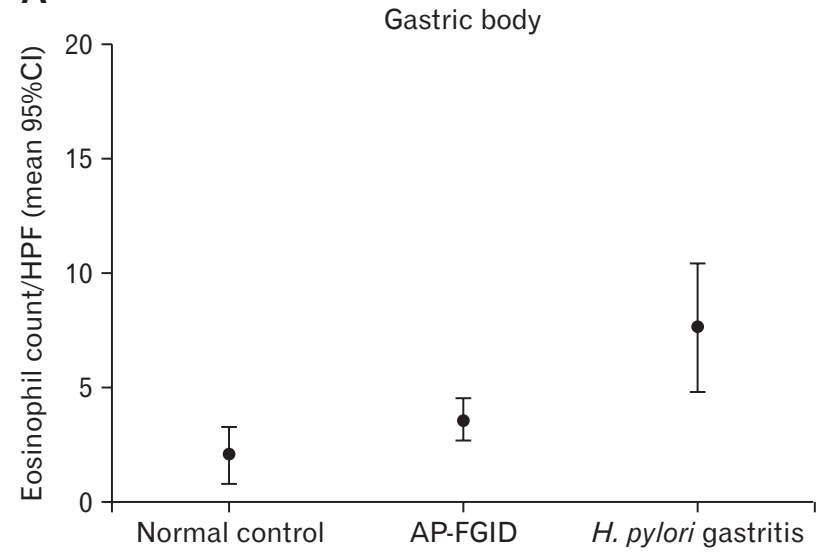

B

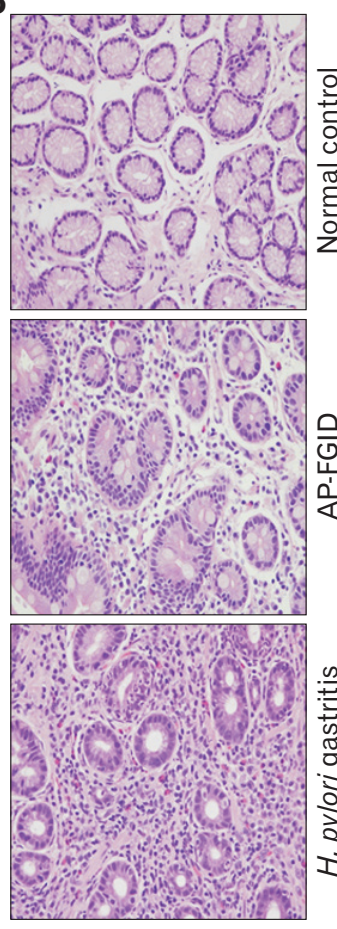

(H\&E, x400)
Figure 1. Eosinophil count in the gastric antrum for normal control, abdominal pain-related functional gastrointestinal disorder (AP-FGID), and Helicobacter pylori (H. pylori) infection. (A) Eosinophil count in the gastric antrum expressed as mean and $95 \% \mathrm{CI}$, $1.9(1.3-2.5) /$ high power field (HPF) in normal controls, $3.9(3.1-4.6) / \mathrm{HPF}$ in AP-FGID, and 12.7 (5.8-19.7)/HPF in Helicobacter pylori gastritis (magnification, $\times 400)$. (B) Photographs of hematoxylin and eosin staining for eosinophils in the gastric antrum from each representative specimen for normal controls, AP-FGID, and $H$. pylori infection.
B

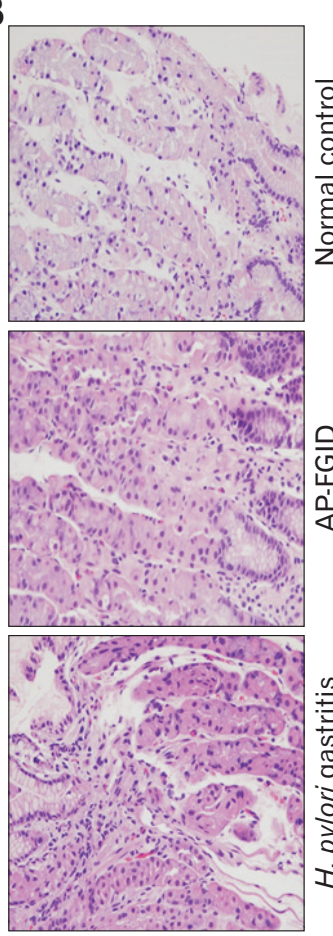

$(H \& E, x 400)$
Figure 2. Eosinophil count in the gastric body for normal control, abdominal pain-related functional gastrointestinal disorder (AP-FGID), and Helicobacter pylori (H. pylori) infection. (A) Eosinophil count in the gastric body expressed as mean and 95\% CI, 2.1 (0.8-3.4)/high power field (HPF) in normal controls, 3.7 (2.7-4.6)/HPF in AP-FGID, and $7.7(4.9-10.5) / \mathrm{HPF}$ in Helicobacter pylori gastritis (magnification, $\times 400$ ). (B) Photographs of hematoxylin and eosin staining for eosinophils in the gastric body from each representative specimen for normal control, AP-FGID, and $H$. pylori infection. 
and the disease control group in gender distribution $(P=0.517)$ or in age $(P=0.150)($ Table 1$)$.

\section{Gastric and Duodenal Eosinophil Counts in Abdominal Pain-related Functional Gastrointestinal Disorder and Normal Control}

Eosinophil counts in the gastric antrum and body were both significantly higher in children with AP-FGID than the normal pediatric reference value (mean 3.9 [95\% CI, 3.1-4.6] eosinophils/ HPF vs mean 1.9 [95\% CI, 1.3-2.5]) eosinophils/HPF, $P<0.001$ for the antrum; mean 3.7 [95\% CI, 2.7-4.6] eosinophils/HPF vs mean 2.1 [95\% CI, 0.8-3.4] eosinophils/HPF, $P=0.045$ for the gastric body, respectively) (Fig. 1 and 2; Table 2). Duodenal eosinophil counts were high in children with AP-FGID, but not significantly when compared with normal reference values (mean 12.3 [95\% CI, 10.5-14.1] eosinophils/HPF vs mean 9.6 [95\% CI, 6.5-12.7] eosinophils/HPF, $P=0.127$ ) (Fig. 3 and Table 2).

When tissue eosinophil counts were compared between each subtype of pediatric AP-FGID identified by the Rome III criteria and the normal control, eosinophil counts of the gastric antrum were significantly different in most subtypes except for AM $(P$ $=0.003$ in FD vs normal control, $P=0.009$ in IBS vs normal control, $P=0.015$ in FAPS vs normal control, and $P=0.147$ in AM vs normal control, respectively). In contrast, there were no

Table 2. Comparison of Gastric and Duodenal Eosinophil Counts Between Children with Abdominal Pain-related Functional Gastrointestinal Disorders and Normal Controls

\begin{tabular}{|c|c|c|c|c|c|}
\hline & \multicolumn{2}{|c|}{$\begin{array}{l}\text { AP-FGID } \\
(\mathrm{n}=105)\end{array}$} & \multicolumn{2}{|c|}{$\begin{array}{l}\text { Normal control } \\
\qquad(\mathrm{n}=19)\end{array}$} & \multirow[t]{2}{*}{$P$-value } \\
\hline & Mean & $95 \% \mathrm{CI}$ & Mean & $95 \% \mathrm{CI}$ & \\
\hline Antrum & 3.9 & $3.1-4.6$ & 1.9 & $1.3-2.5$ & $<0.001$ \\
\hline Body & 3.7 & $2.7-4.6$ & 2.1 & $0.8-3.4$ & 0.045 \\
\hline Duodenum & 12.3 & $10.5-14.1$ & 9.6 & $6.5-12.7$ & 0.127 \\
\hline
\end{tabular}

AP-FGID, abdominal pain-related functional gastrointestinal disorder.

The mean number and 95\% CI of eosinophils/high-power field for each anatomical region of the upper gastrointestinal tract.

$P$-value was calculated by independent $t$ test.

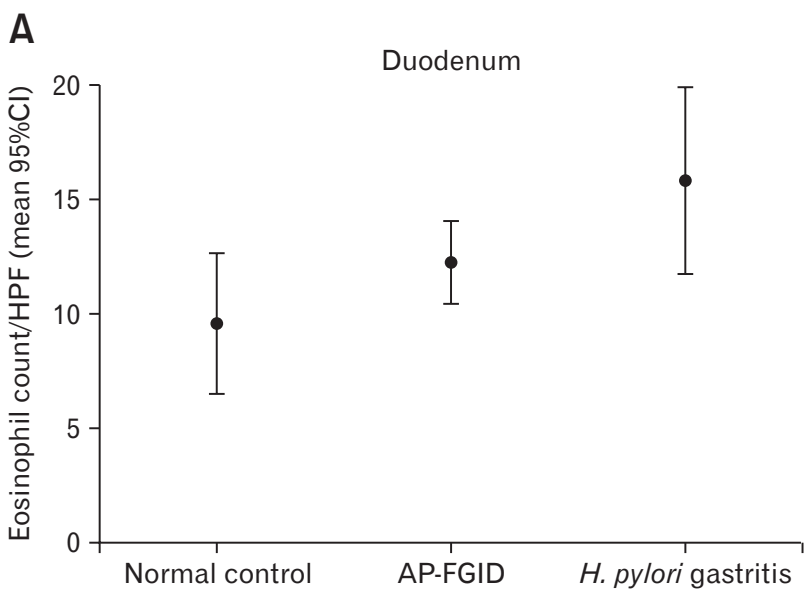

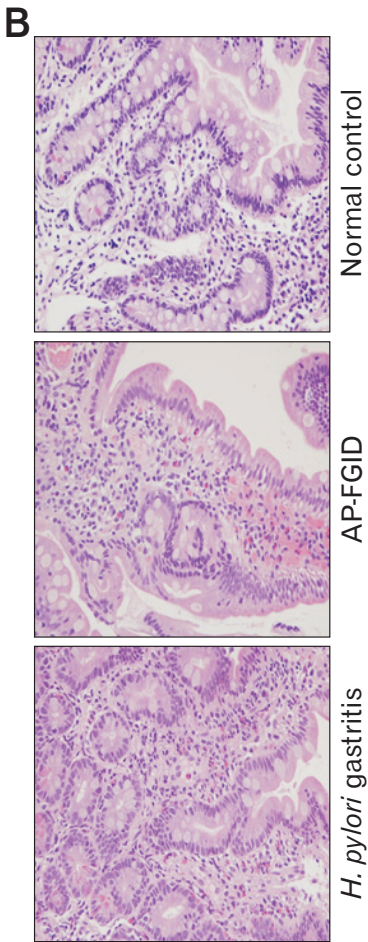

$(H \& E, x 400)$
Figure 3. Eosinophil count in the duodenum for normal control, abdominal pain-related functional gastrointestinal disorder (AP-FGID), and Helicobacter pylori infection. (A) Eosinophil count in the duodenum expressed as mean and 95\% CI, 9.6 (6.5-12.7)/high power field (HPF) in normal controls, 12.3 (10.514.1)/HPF in AP-FGID, and 15.9 (11.8-20.0)/HPF in Helicobacter pylori (H. pylori) gastritis (magnification, $\times 400$ ). (B) Photographs of hematoxylin and eosin staining for eosinophils in the duodenum from each representative specimen for normal controls, APFGID, and $H$. pylori infection. 
significant differences in eosinophil counts of the gastric body and duodenum when comparing each AP-FGID subtype with the normal control (Table 3$)$.

\section{Gastric and Duodenal Eosinophil Counts Among the Subtypes of Abdominal Pain-related Functional Gastrointestinal Disorder in Children}

There were no statistically significant differences in tissue eosinophil counts for the gastric antrum, gastric body, and duodenum

Table 3. Comparison of Tissue Eosinophil Counts Between Each Subtype of Abdominal Pain-related Functional Gastrointestinal Disorder and Normal Controls

\begin{tabular}{|c|c|c|c|c|c|}
\hline \multirow[t]{2}{*}{ Biopsy site } & \multicolumn{2}{|c|}{$\begin{array}{l}\text { AP-FGID } \\
(\mathrm{n}=105)\end{array}$} & \multicolumn{2}{|c|}{$\begin{array}{l}\text { Normal control } \\
\qquad(\mathrm{n}=19)\end{array}$} & \multirow[t]{2}{*}{$P$-value } \\
\hline & Mean & $95 \% \mathrm{CI}$ & Mean & $95 \% \mathrm{CI}$ & \\
\hline \multicolumn{6}{|c|}{ H2a. Functional dyspepsia $(n=43)$} \\
\hline Antrum & 4.3 & $2.9-5.7$ & 1.9 & $1.3-2.5$ & 0.003 \\
\hline Body & 4.0 & $2.5-5.4$ & 2.1 & $0.8-3.4$ & 0.057 \\
\hline Duodenum & 13.4 & $10.6-16.2$ & 9.6 & $6.5-12.7$ & 0.066 \\
\hline \multicolumn{6}{|c|}{ H2b. Irritable bowel syndrome $(n=40)$} \\
\hline Antrum & 3.7 & $2.5-4.9$ & 1.9 & $1.3-2.5$ & 0.009 \\
\hline Body & 3.3 & $1.8-4.8$ & 2.1 & $0.8-3.4$ & 0.217 \\
\hline Duodenum & 12.1 & $9.1-15.0$ & 9.6 & $6.5-12.7$ & 0.236 \\
\hline \multicolumn{6}{|l|}{ H2c. Abdominal migraine $(n=6)$} \\
\hline Antrum & 4.8 & $0.6-9.0$ & 1.9 & $1.3-2.5$ & 0.147 \\
\hline Body & 3.8 & $-1.3-8.9$ & 2.1 & $0.8-3.4$ & 0.417 \\
\hline Duodenum & 7.6 & $4.2-11.0$ & 9.6 & $6.5-12.7$ & 0.305 \\
\hline \multicolumn{6}{|c|}{$\mathrm{H} 2 \mathrm{~d}$. Functional abdominal pain syndrome $(\mathrm{n}=21)$} \\
\hline Antrum & 4.0 & $2.4-5.6$ & 1.9 & $1.3-2.5$ & 0.015 \\
\hline Body & 3.8 & $1.7-5.8$ & 2.1 & $0.8-3.4$ & 0.154 \\
\hline Duodenum & 12.2 & $6.9-17.4$ & 9.6 & $6.5-12.7$ & 0.390 \\
\hline
\end{tabular}

AP-FGID, abdominal pain-related functional gastrointestinal disorder.

The mean number and $95 \% \mathrm{CI}$ of eosinophils per high-power field for each anatomical region of the upper gastrointestinal tract.

$P$-value was calculated by independent $t$ test.

Table 4. Comparison of Tissue Eosinophil Counts Among the 4 Subtypes of Abdominal Pain-related Functional Gastrointestinal Disorder in Children

\begin{tabular}{|c|c|c|c|c|}
\hline Biopsy site & AP-FGID subtype & Median (range) & Mean $\pm \mathrm{SD}$ & $P$-value \\
\hline \multirow{4}{*}{ Gastric antrum } & FD & $3.0(0-15)$ & $3.9 \pm 4.1$ & 0.852 \\
\hline & IBS & $2.0(0-15)$ & $3.2 \pm 2.7$ & \\
\hline & $\mathrm{AM}$ & $3.0(1-10)$ & $4.7 \pm 4.7$ & \\
\hline & FAPS & $4.0(0-14)$ & $4.0 \pm 3.4$ & \\
\hline \multirow[t]{4}{*}{ Gastric body } & FD & $1.0(0-20)$ & $3.8 \pm 4.9$ & 0.888 \\
\hline & IBS & $2.0(0-21)$ & $3.3 \pm 4.6$ & \\
\hline & $\mathrm{AM}$ & $2.0(1-10)$ & $4.3 \pm 4.9$ & \\
\hline & FAPS & $2.0(0-15)$ & $3.8 \pm 4.4$ & \\
\hline \multirow[t]{4}{*}{ Duodenum } & $\mathrm{FD}$ & $10.5(1-42)$ & $12.9 \pm 8.4$ & 0.438 \\
\hline & IBS & $9.0(1-40)$ & $11.6 \pm 8.3$ & \\
\hline & $\mathrm{AM}$ & $6.0(5-7)$ & $6.0 \pm 2.0$ & \\
\hline & FAPS & $9.5(0-50)$ & $12.2 \pm 11.2$ & \\
\hline
\end{tabular}

AP-FGID, abdominal pain related functional gastrointestinal disorder; FD, functional dyspepsia; IBS, irritable bowel syndrome; AM, abdominal migraine; FAPS, functional abdominal pain or syndrome.

Eosinophils per high power field for each anatomical region of the upper gastrointestinal tract.

$P$-value was calculated by Kruskal-Wallis test. 
Table 5. Pair-wise Comparison of Tissue Eosinophil Counts Between the Subtypes of Abdominal Pain-related Functional Gastrointestinal Disorder in Children

\begin{tabular}{lccc}
\hline & $\begin{array}{c}\text { Antrum } \\
(P \text {-value })\end{array}$ & $\begin{array}{c}\text { Body } \\
(P \text {-value })\end{array}$ & $\begin{array}{c}\text { Duodenum } \\
(P \text {-value })\end{array}$ \\
\hline FD vs IBS & 0.983 & 0.973 & 0.349 \\
FD vs FAPS & 0.644 & 0.658 & 0.432 \\
IBS vs FAPS & 0.384 & 0.598 & 0.820 \\
FD vs AM & 0.561 & 0.474 & 0.131 \\
IBS vs AM & 0.584 & 0.572 & 0.267 \\
FAPS vs AM & 0.895 & 0.795 & 0.388 \\
\hline
\end{tabular}

FD, functional dyspepsia; IBS, irritable bowel syndrome; FAPS, functional abdominal pain or syndrome; AM, abdominal migraine. $P$-value was calculated by Mann-Whitney $U$ test.

Table 6. Comparison of Tissue Eosinophil Counts Between Children with Abdominal Pain-related Functional Gastrointestinal Disorder and Those with Helicobacter pylori Gastritis

\begin{tabular}{|c|c|c|c|c|c|}
\hline & \multicolumn{2}{|c|}{$\begin{array}{l}\text { AP-FGID } \\
(\mathrm{n}=105)\end{array}$} & \multicolumn{2}{|c|}{$\begin{array}{l}\text { H. pylori gastritis } \\
\qquad(\mathrm{n}=27)\end{array}$} & \multirow[t]{2}{*}{$P$-value } \\
\hline & Mean & $95 \% \mathrm{CI}$ & Mean & $95 \% \mathrm{CI}$ & \\
\hline Antrum & 3.9 & $3.1-4.6$ & 12.7 & $5.8-19.7$ & $<0.001$ \\
\hline Body & 3.7 & $2.7-4.6$ & 7.7 & $4.9-10.5$ & 0.002 \\
\hline Duodenum & 12.3 & $10.5-14.1$ & 15.9 & $11.8-20.0$ & 0.057 \\
\hline
\end{tabular}

AP-FGID, abdominal pain-related functional gastrointestinal disorder; H. pylori, Helicobacter pylori.

The mean number and $95 \% \mathrm{CI}$ of eosinophils/high-power field for each anatomical region of the upper gastrointestinal tract.

$P$-value was calculated by Mann-Whitney $\mathrm{U}$ test.

among the 4 subtypes of AP-FGID (Table 4). In addition, there were also no significant differences in eosinophil counts of the stomach and duodenum in pair-wise comparisons between the subtypes of AP-FGID (Table 5).

\section{Gastric and Duodenal Eosinophil Counts in Abdominal Pain-related Functional Gastrointestinal Disorder and Helicobacter pylori Infection Group}

In children with $H$. pylori infection, mean eosinophil counts in endoscopic biopsies were as follows: 12.7 (95\% CI, 5.8-19.7) eosinophils/HPF in the gastric antrum, 7.7 (95\% CI, 4.9-10.5) eosinophils/HPF in the gastric body, and 15.9 (95\% CI, 11.8-20.0) eosinophils/HPF in the duodenum. The gastric antrum and gastric body eosinophil counts were significantly higher in children with $H$. pylori infection than in those with AP-FGID $(P<0.001$ in the antrum, $P=0.002$ in the gastric body, respectively) (Fig. 1 and 2; Table 6). Duodenal eosinophil counts were high in children with $H$. pylori infection, but not significantly when compared to those with $\operatorname{AP-FGID}(P=0.057)$ (Fig. 3 and Table 6).

When eosinophil counts of the gastric antrum and body were compared according to the degree of histologic inflammation based on the Sydney classification at the same site between children with AP-FGID and those with $H$. pylori infection, significant correlations between tissue eosinophil counts and histologic inflammation in the gastric antrum and body were noted (Spearman's correlation coefficient $r=0.364, r^{2}=0.292, P<0.001$ and $r=0.264, r^{2}=$ $0.076, P=0.003$ for eosinophils vs neutrophils in the antrum and body, respectively; $r=0.410, r^{2}=0.186, P<0.001$ and $r=0.343$, $r^{2}=0.115, P<0.001$ for eosinophils vs mononuclear cells in the antrum and body, respectively).

\section{Discussion}

The aim of this study was to evaluate the association of gastric and duodenal eosinophilia with pediatric AP-FGID, so as to better understand its pathogenesis. The mechanism of AP-FGID is not clearly known yet, and multidisciplinary interpretation has been suggested through a biopsychosocial model. ${ }^{10}$ Recent studies suggest that micro-inflammation of the intestines is essentially involved in the pathophysiology of FGID. ${ }^{16}$ Adult studies on FGID, especially FD and IBS, ${ }^{13,14}$ have found that increased infiltration of eosinophils, mast cells, and intraepithelial lymphocytes represent low- 
grade mucosal inflammation in the gastrointestinal tract.

It is not clear how low-grade inflammation occurs, but it has been suggested that gut barrier dysfunction facilitates the penetration of antigens through the gastrointestinal mucosal epithelium in IBS and inflammatory bowel disease, which provokes an immune response. $^{42,43}$ For instance, perturbation of luminal contents, such as dietary antigens or gastrointestinal pathogens, through an abnormally increased intestinal permeability may facilitate an inappropriate stimulation of the host immune response in post-infectious IBS patients. ${ }^{12,44}$ Increased infiltration of the lamina propria $T$ cells, mast cells, and enterochromaffin cells have also been observed in the colon or ileum of patients with post-infectious IBS. ${ }^{30}$ The mediators released by these activated cells types may stimulate sensory afferent pathways and induce visceral hyperalgesia. ${ }^{18} \mathrm{~A}$ recent study demonstrated decreased duodenal mucosal integrity, increased permeability, and low-grade inflammation caused by increased infiltration of mast cells, intraepithelial cells, and eosinophils in patients with FD. ${ }^{13}$ In the aforementioned study, the researchers hypothesized that impaired barrier function could facilitate the passage of luminal antigens through the epithelium to the lamina propria, thereby lowgrade inflammation develop and persists. ${ }^{13}$

Eosinophils are activated by an inflammatory reaction that is initiated by internal and external triggers. ${ }^{16,45}$ Internal triggers, such as anxiety and stress, impinge on gut physiology through the braingut axis to induce an inflammatory response, whereas external triggers, such as microbes and allergens, stimulate inflammation via highly-conserved, pathogen-associated molecular patterns. ${ }^{16,46}$ With the release of cytokines, such as IL-4, IL-5, and IL-13 from type 2 $\mathrm{T}$ helper cells during the inflammatory response, activated eosinophils are ready for massive degranulation. ${ }^{11,16,20,47}$ Degranulation contents, such as the nerve growth factor, have a direct influence on sensory nerves, and major basic proteins can induce vagal nerve muscarinic receptor 2 dysfunction. ${ }^{19,20}$ Platelet aggregating factor, leukotrienes, and IL-13 are also able to act directly on the smooth muscle cells, thereby increasing contractility and reactivity. ${ }^{19,20}$ Thus, the accumulation and degranulation of eosinophils gives rise to neural stimulation and smooth muscle contraction, which consequently produces gastrointestinal symptoms, such as abdominal cramps, abdominal discomfort, and flatulence. ${ }^{16,19,20,48}$

According to a study by Schappi et al, ${ }^{49}$ children with atopic FD demonstrated increased eosinophils and mast cells within the antrum, and these cells degranulated rapidly after a cow's milk challenge unlike in children with non-atopic FD. Duodenal eosinophilia can be associated with an allergy, ${ }^{20}$ and eosinophils in the duodenum can be activated in patients with allergy-related disorders, includ- ing asthma and atopic eczema, which can induce gastrointestinal symptoms in these groups of patients. ${ }^{11,50,51}$ To eliminate the factors which can affect eosinophil activation in the gastrointestinal tract, we excluded in the present study patients who had a significant allergy, including food allergy, asthma, atopic dermatitis, and allergic rhinitis.

We hypothesized that micro-inflammation might be the main pathogenesis that gives rise to gastrointestinal symptoms in APFGID, as such, we expected inflammatory cell densities in the stomach and the duodenum of the AP-FGID group to be higher than those of normal controls without any symptoms, and lower than those of the $H$. pylori infection group with definite inflammation. Previous studies show that an $H$. pylori infection results in significantly higher tissue inflammatory cell densities, including lymphocytes, plasma cells, neutrophils, mast cells, and eosinophils. ${ }^{52-55}$ Likewise, in the present study, eosinophil counts of the gastric antrum and body were significantly high in the order of the H. pylori infection group, AP-FGID group, and normal controls; however, duodenal eosinophil counts were not significantly different. Although the difference between mean duodenal eosinophil counts in patients with AP-FGID and that of normal controls was not statistically significant, it might be notable that duodenal eosinophil counts in AP-FGID patients in our study were still more than 10 cells/HPF in most cases, and duodenal eosinophilia have previous been defined as $>10$ cells/HPF for children. ${ }^{20,56}$

There were no statistically significant differences in tissue eosinophil counts of the gastric antrum, gastric body, and duodenum among the 4 subtypes of AP-FGID in this study. Further study, that targets a large number of children within each subtype of pediatric AP-FGID, may still be required to evaluate if tissue eosinophil infiltration is different in the entire gastrointestinal tract according to the subtype of pediatric AP-FGID.

Previously published studies demonstrated that eosinophil density in the duodenum was higher in adult patients with FD than in healthy controls, but this was not applied to the density of gastric eosinophils. ${ }^{16,21}$ In our study, eosinophil counts of the gastric antrum were significantly higher in children with FD than in normal controls, and duodenal eosinophil counts were high in children with FD; but this difference was not significant when compared with the normal reference value. Histopathological findings of the present study, confirming that antral eosinophils were significantly activated in children with FD, are consistent with the results of a previous study. ${ }^{37}$ The results of this present study is different with that of previous studies except for Friesen et al's study, in the way that gastric eosinophil count is associated with AP-FGID. The exact cause that 
can account for this different result is not proven and further succeeding studies are still needed to explain the significance of gastric eosinophilia in pediatric AP-FGID. In our study, all children with AP-FGID underwent esophagogastroduodenoscopy with biopsy due to the red flag signs along with chronic abdominal pain; hence, our patients might indicate a more severe disease status and raise the likelihood of overestimation. Nevertheless, eosinophil densities of children with FD in our study was relatively lower in comparison to those from two previous studies, which report a mean eosinophil density of $7.1 \pm 5.5 / \mathrm{HPF}$ in the antrum of children with $\mathrm{FD}$, and $10.3 \pm 10.1 / \mathrm{HPF}$ in the antrum and $21.2 \pm 11.5 / \mathrm{HPF}$ in duodenal bulb of children with FD. ${ }^{36,37}$

In addition, in the present study, we graded the intensity of neutrophil and mononuclear cell infiltration in the stomach using the updated Sydney classification, and compared gastric eosinophil counts with infiltrates of neutrophil and mononuclear cells in order to determine if the degree of eosinophil infiltration correlated with that of other inflammatory cell infiltrations. Accordingly, we were able to verify the association of tissue eosinophil counts with histologic inflammation in the gastric antrum and body, because our study revealed significant correlations between tissue eosinophil counts and histologic inflammation in the gastric antrum and body.

Nevertheless, the present study also has some limitations that remain to be addressed. First, this study did not enroll healthy individuals as part of the normal control group because ethical considerations do not justify endoscopic examination with biopsy sampling for eosinophilic infiltration evaluation in otherwise healthy children. Therefore, as a substitute for recruiting a normal control group, we derived normal reference values based on a previously published study, which evaluated endoscopic biopsies from each region of the gastrointestinal tract for pediatric patients with no identified organic gastrointestinal disease based on histological criteria, endoscopic findings, and final clinical assess. ${ }^{40}$ This reference group, however, was not comprised of Korean children and therefore might not be able to represent a precise normal control; this group also included some patients with functional abdominal pain, and some patients with allergies, such as asthma, eczema, and rhinitis. As a result, the normal reference values used in this study were likely to reflect elevated tissue eosinophil counts than that of truly normal individuals. Second, this study incorporates a retrospective analysis and the sample size of this study is relatively small, particularly with regards to the normal control and $H$. pylori infection groups. As such, further prospectively designed studies targeting a large number of pediatric patients and including additional cell types, such as mast cells or intra-epithelial lymphocytes are still needed to confirm low- grade inflammation in pediatric AP-FGID.

In conclusion, gastric antrum and gastric body eosinophil counts were significantly higher in children with AP-FGID in comparison to normal reference values, and lower than those with $H$. pylori infection in our study; whereas, duodenal eosinophil counts of AP-FGID were not significantly different from normal controls or those with an $H$. pylori infection. In addition, there were no significant differences in eosinophil counts of the stomach or duodenum among the 4 subtypes of AP-FGID, based on the Rome III criteria in children.

The present study reveals that gastric eosinophilia, rather than duodenal eosinophilia might be associated with AP-FGID in children. Therefore, the results of our study suggest that there might be some contributions of gastrointestinal eosinophils to the development of pediatric AP-FGID.

\section{Financial support: None.}

\section{Conflicts of interest: None.}

Author contributions: Eun Hye Lee: conducting the study, collecting and interpreting data, drafting the manuscript; Hye Ran Yang: planning the study, interpreting data, drafting the manuscript; and Hye Seung Lee: conducting the study, collecting and interpreting data.

\section{References}

1. Korterink JJ, Diederen K, Benninga MA, Tabbers MM. Epidemiology of pediatric functional abdominal pain disorders: a meta-analysis. PLoS One 2015;10:e126982.

2. Youssef NN, Atienza K, Langseder AL, Strauss RS. Chronic abdominal pain and depressive symptoms: analysis of the national longitudinal study of adolescent health. Clin Gastroenterol Hepatol 2008;6:329-332.

3. Drossman DA, Li Z, Andruzzi E, et al. U.S. householder survey of functional gastrointestinal disorders. Prevalence, sociodemography, and health impact. Dig Dis Sci 1993;38:1569-1580.

4. Saps M, Biring HS, Pusatcioglu CK, Mintjens S, Rzeznikiewiz D. A comprehensive review of randomized placebo-controlled pharmacological clinical trials in children with functional abdominal pain disorders. J Pediatr Gastroenterol Nutr 2015;60:645-653.

5. Di Lorenzo C, Colletti RB, Lehmann HP, et al. Chronic abdominal pain in children: a technical report of the American Academy of Pediatrics and the North American Society for Pediatric Gastroenterology, Hepatology and Nutrition. J Pediatr Gastroenterol Nutr 2005;40:249-261.

6. Drossman DA. The functional gastrointestinal disorders and the Rome III process. Gastroenterology 2006;130:1377-1390.

7. Simrén M, Barbara G, Flint HJ, et al. Intestinal microbiota in functional 
bowel disorders: a Rome foundation report. Gut 2013;62:159-176.

8. Koloski NA, Jones M, Kalantar J, Weltman M, Zaguirre J, Talley NJ. The brain-gut pathway in functional gastrointestinal disorders is bidirectional: a 12-year prospective population-based study. Gut 2012;61:12841290.

9. Chelimsky G, Boyle JT, Tusing L, Chelimsky TC. Autonomic abnormalities in children with functional abdominal pain: coincidence or etiology? J Pediatr Gastroenterol Nutr 2001;33:47-53.

10. Friesen CA, Schurman JV, Colombo JM, Abdel-Rahman SM. Eosinophils and mast cells as therapeutic targets in pediatric functional dyspepsia. World J Gastrointest Pharmacol Ther 2013;4:86-96.

11. Walker MM, Warwick A, Ung C, Talley NJ. The role of eosinophils and mast cells in intestinal functional disease. Curr Gastroenterol Rep 2011;13:323-330.

12. Ford AC, Talley NJ. Mucosal inflammation as a potential etiological factor in irritable bowel syndrome: a systematic review. J Gastroenterol 2011;46:421-431.

13. Vanheel H, Vicario M, Vanuytsel T, et al. Impaired duodenal mucosal integrity and low-grade inflammation in functional dyspepsia. Gut 2014;63:262-271.

14. Walker MM, Talley NJ, Prabhakar M, et al. Duodenal mastocytosis, eosinophilia and intraepithelial lymphocytosis as possible disease markers in the irritable bowel syndrome and functional dyspepsia. Aliment Pharmacol Ther 2009;29:765-773.

15. Dunlop SP, Jenkins D, Spiller RC. Distinctive clinical, psychological, and histological features of postinfective irritable bowel syndrome. Am J Gastroenterol 2003;98:1578-1583.

16. Wang X, Li X, Ge W, et al. Quantitative evaluation of duodenal eosinophils and mast cells in adult patients with functional dyspepsia. Ann Diagn Pathol 2015;19:50-56.

17. Walker MM, Aggarwal KR, Shim LS, et al. Duodenal eosinophilia and early satiety in functional dyspepsia: confirmation of a positive association in an Australian cohort. J Gastroenterol Hepatol 2014;29:474-479.

18. Lee KJ, Tack J. Duodenal implications in the pathophysiology of functional dyspepsia. J Neurogastroenterol Motil 2010;16:251-257.

19. Rothenberg ME, Cohen MB. An eosinophil hypothesis for functional dyspepsia. Clin Gastroenterol Hepatol 2007;5:1147-1148.

20. Walker MM, Salehian SS, Murray CE, et al. Implications of eosinophilia in the normal duodenal biopsy - an association with allergy and functional dyspepsia. Aliment Pharmacol Ther 2010;31:1229-1236.

21. Talley NJ, Walker MM, Aro P, et al. Non-ulcer dyspepsia and duodenal eosinophilia: an adult endoscopic population-based case-control study. Clin Gastroenterol Hepatol 2007;5:1175-1183.

22. Hall W, Buckley M, Crotty P, O'Morain CA. Gastric mucosal mast cells are increased in Helicobacter pylori-negative functional dyspepsia. Clin Gastroenterol Hepatol 2003;1:363-369.

23. Matter SE, Bhatia PS, Miner PB Jr. Evaluation of antral mast cells in nonulcer dyspepsia. Dig Dis Sci 1990;35:1358-1363.

24. Li X, Chen H, Lu H, et al. The study on the role of inflammatory cells and mediators in post-infectious functional dyspepsia. Scand J Gastroenterol 2010;45:573-581.

25. Guilarte M, Santos J, de Torres I, et al. Diarrhoea-predominant IBS patients show mast cell activation and hyperplasia in the jejunum. Gut 2007;56:203-209.

26. Weston AP, Biddle WL, Bhatia PS, Miner PB Jr. Terminal ileal mucosal mast cells in irritable bowel syndrome. Dig Dis Sci 1993;38:1590-1595.

27. Coëffier M, Gloro R, Boukhettala N, et al. Increased proteasomemediated degradation of occludin in irritable bowel syndrome. Am J Gastroenterol 2010;105:1181-1188.

28. Bian ZX, Li Z, Huang ZX, et al. Unbalanced expression of proteaseactivated receptors- 1 and -2 in the colon of diarrhea-predominant irritable bowel syndrome patients. J Gastroenterol 2009;44:666-674.

29. Cremon C, Gargano L, Morselli-Labate AM, et al. Mucosal immune activation in irritable bowel syndrome: gender-dependence and association with digestive symptoms. Am J Gastroenterol 2009;104:392-400.

30. Lee KJ, Kim YB, Kim JH, Kwon HC, Kim DK, Cho SW. The alteration of enterochromaffin cell, mast cell, and lamina propria T lymphocyte numbers in irritable bowel syndrome and its relationship with psychological factors. J Gastroenterol Hepatol 2008;23:1689-1694.

31. Piche T, Saint-Paul MC, Dainese R, et al. Mast cells and cellularity of the colonic mucosa correlated with fatigue and depression in irritable bowel syndrome. Gut 2008;57:468-473.

32. Cenac N, Andrews CN, Holzhausen M, et al. Role for protease activity in visceral pain in irritable bowel syndrome. J Clin Invest 2007;117:636647.

33. Tornblom H, Lindberg G, Nyberg B, Veress B. Full-thickness biopsy of the jejunum reveals inflammation and enteric neuropathy in irritable bowel syndrome. Gastroenterology 2002;123:1972-1979.

34. O'Sullivan M, Clayton N, Breslin NP, et al. Increased mast cells in the irritable bowel syndrome. Neurogastroenterol Motil 2000;12:449-457.

35. Friesen CA, Andre L, Garola R, Hodge C, Roberts C. Activated duodenal mucosal eosinophils in children with dyspepsia: a pilot transmission electron microscopic study. J Pediatr Gastroenterol Nutr 2002;35:329333.

36. Friesen CA, Neilan NA, Schurman JV, Taylor DL, Kearns GL, AbdelRahman SM. Montelukast in the treatment of duodenal eosinophilia in children with dyspepsia: effect on eosinophil density and activation in relation to pharmacokinetics. BMC Gastroenterol 2009;9:32.

37. Friesen CA, Lin Z, Singh M, et al. Antral inflammatory cells, gastric emptying, and electrogastrography in pediatric functional dyspepsia. Dig Dis Sci 2008;53:2634-2640.

38. Schurman JV, Singh M, Singh V, Neilan N, Friesen CA. Symptoms and subtypes in pediatric functional dyspepsia: relation to mucosal inflammation and psychological functioning. J Pediatr Gastroenterol Nutr 2010;51:298-303.

39. Mahjoub FE, Farahmand F, Pourpak Z, Asefi H, Amini Z. Mast cell gastritis: children complaining of chronic abdominal pain with histologically normal gastric mucosal biopsies except for increase in mast cells, proposing a new entity. Diagn Pathol 2009;4:34.

40. DeBrosse CW, Case JW, Putnam PE, Collins MH, Rothenberg ME. Quantity and distribution of eosinophils in the gastrointestinal tract of children. Pediatr Dev Pathol 2006;9:210-218.

41. Dixon MF, Genta RM, Yardley JH, Correa P. Classification and grading of gastritis. The updated Sydney System. International Workshop 
on the Histopathology of Gastritis, Houston 1994. Am J Surg Pathol 1996;20:1161-1181.

42. Ohman L, Simrén M. Pathogenesis of IBS: role of inflammation, immunity and neuroimmune interactions. Nat Rev Gastroenterol Hepatol 2010;7:163-173.

43. Salim SY, Söderholm JD. Importance of disrupted intestinal barrier in inflammatory bowel diseases. Inflamm Bowel Dis 2011;17:362-381.

44. Marshall JK, Thabane M, Garg AX, Clark W, Meddings J, Collins SM. Intestinal permeability in patients with irritable bowel syndrome after a waterborne outbreak of acute gastroenteritis in Walkerton, Ontario. Aliment Pharmacol Ther 2004;20:1317-1322.

45. Thumshirn M. Pathophysiology of functional dyspepsia. Gut 2002;51(suppl 1):i63-i66.

46. Tack J, Bisschops R, Sarnelli G. Pathophysiology and treatment of functional dyspepsia. Gastroenterology 2004;127:1239-1255.

47. Rothenberg ME, Mishra A, Collins MH, Putnam PE. Pathogenesis and clinical features of eosinophilic esophagitis. J Allergy Clin Immunol 2001;108:891-894.

48. Powell N, Walker MM, Talley NJ. Gastrointestinal eosinophils in health, disease and functional disorders. Nat Rev Gastroenterol Hepatol 2010;7:146-156.

49. Schappi MG, Borrelli O, Knafelz D, et al. Mast cell-nerve interactions in children with functional dyspepsia. J Pediatr Gastroenterol Nutr 2008;47:472-480.
50. Pires GV, Souza HS, Elia CC, et al. Small bowel of patients with asthma and allergic rhinitis: absence of inflammation despite the presence of major cellular components of allergic inflammation. Allergy Asthma Proc 2004;25:253-259.

51. Wallaert B, Desreumaux P, Copin MC, et al. Immunoreactivity for interleukin 3 and 5 and granulocyte/macrophage colony-stimulating factor of intestinal mucosa in bronchial asthma. J Exp Med 1995;182:1897-1904.

52. Ashorn M, Ruuska T, Karikoski R, Välipakka J, Mäki M. Gastric mucosal cell densities in Helicobacter pylori-positive and -negative dyspeptic children and healthy controls. J Pediatr Gastroenterol Nutr 1994;18:146151.

53. Lin Z, Chen JD, Parolisi S, Shifflett J, Peura DA, McCallum RW. Prevalence of gastric myoelectrical abnormalities in patients with nonulcer dyspepsia and $H$. pylori infection: resolution after $H$. pylori eradication. Dig Dis Sci 2001;46:739-745.

54. Kalach N, Huvenne H, Gosset P, et al. Eosinophil counts in upper digestive mucosa of Western European children: variations with age, organs, symptoms, Helicobacter pylori status, and pathological findings. J Pediatr Gastroenterol Nutr 2011;52:175-182.

55. Sulik A, Kemona A, Sulik M, Oldak E. [Mast cells in chronic gastritis of children.] Pol Merkur Lekarski 2001;10:156-160. [Polish]

56. Lowichik A, Weinberg AG. A quantitative evaluation of mucosal eosinophils in the pediatric gastrointestinal tract. Mod Pathol 1996;9:110-114. 